\title{
Análise de trilha em caracteres de frutos de jabuticabeira
}

\author{
Vanessa Padilha Salla ${ }^{(1)}$, Moeses Andrigo Danner(2), Idemir Citadin ${ }^{(1)}$, Simone Aparecida Zolet Sasso(1), \\ Joel Donazzolo(2) e Bruna Valéria Gi(l(2)
}

\begin{abstract}
(1)Universidade Tecnológica Federal do Paraná (UTFPR), Campus Pato Branco, Via do Conhecimento, Km 01, Caixa Postal 571, CEP 85503-390 Pato Branco, PR, Brasil. E-mail: vanessa_pad@hotmail.com, idemir@utfpr.edu.br, simonezoletsasso@hotmail.com (2)UTFPR, Campus Dois Vizinhos, Estrada para Boa Esperança, Km 04, CEP 85660-000 Dois Vizinhos, PA, Brasil. E-mail: moesesdanner@utfpr.edu.br, joel@utfpr.edu.br, brunnagil@hotmail.com
\end{abstract}

Resumo - O objetivo deste trabalho foi identificar os efeitos diretos e indiretos de caracteres dos frutos de jabuticabeira (Plinia cauliflora) sobre o rendimento de polpa e o teor de antocianinas na casca. Foram coletados frutos de 36 jabuticabeiras, em cinco locais de ocorrência, na região Sudoeste do Paraná. Diferentes estratégias de análise de trilha foram utilizadas na avaliação dos seguintes caracteres dos frutos: peso e diâmetro; rendimento de polpa; percentual de sementes e casca; teores de sólidos solúveis totais, acidez titulável, antocianinas e flavonoides; e número de sementes por fruto. A estratégia de análise de trilha com regressão em crista teve melhor desempenho que a de análise com exclusão de caracteres, principalmente sob presença de multicolinearidade severa no conjunto de dados. O percentual de polpa e o teor de sólidos solúveis totais podem servir de critérios de seleção indireta no aumento do teor de antocianinas na casca da jabuticaba. O percentual de casca é a principal característica com efeito determinante no percentual de polpa de jabuticabas, e a seleção indireta para frutos com menor quantidade de casca pode ser eficaz para aumentar o rendimento de polpa.

Termos para indexação: Plinia cauliflora, antocianinas, multicolinearidade, regressão em crista, rendimento de polpa, seleção indireta.

\section{Path analysis of jabuticaba tree fruit traits}

\begin{abstract}
The objective of this work was to identify the direct and indirect effects of jabuticaba (Plinia cauliflora) fruit traits on pulp yield and anthocyanin content in the peel. Fruit from 36 jabuticaba trees were collected at five occurrence sites in the Southwestern region of the state of Paraná, Brazil. Different path analysis strategies were used in the evaluation of the following fruit traits: weight and diameter; pulp yield; seed and peel percentages; contents of total soluble solids, titratable acidity, anthocyanin, and flavonoid; and number of seeds per fruit. Ridge path analysis strategy had better performance than the analysis with the exclusion of traits, particularly under the presence of severe multicollinearity in the data set. Pulp percentage and total soluble solid content can serve as indirect selection parameters for increasing anthocyanin content in jabuticaba peel. Peel percentage is the main trait with determinant effect on jabuticaba pulp percentage, and the indirect selection for fruit with smaller amount of peel can be effective to increase pulp yield.
\end{abstract}

Index terms: Plinia cauliflora, anthocyanin, multicollinearity, ridge path analysis, pulp yield, indirect selection.

\section{Introdução}

Apesar do potencial de comercialização da jabuticaba [Plinia cauliflora (Mart.) Kausel] (Balerdi et al., 2006), e do interesse no elevado conteúdo de antocianinas e flavonoides em sua casca (Teixeira et al., 2008; Danner et al., 2011), ainda são poucos os pomares plantados com a espécie, com cultivo concentrado principalmente nos estados de São Paulo, Minas Gerais e Goiás. Para que a área de cultivo aumente, é fundamental o desenvolvimento de pesquisas que visem ao avanço na domesticação da espécie.
Por se tratar de uma espécie perene, com longo período juvenil, a seleção e outros processos do melhoramento genético tendem a ser demorados. Nesse sentido, para facilitar a seleção de genótipos promissores, o estudo de correlações entre caracteres é muito importante. Porém, os coeficientes de correlação permitem estimar apenas a magnitude e o sentido das associações lineares entre dois caracteres, e não consideram a influência de outros caracteres na associação. Já a análise de trilha, proposta por Wright (1921), possibilita o desdobramento do coeficiente de correlação em efeitos diretos e indiretos de um grupo 
de caracteres (variáveis explicativas) sobre a expressão de uma variável principal (básica), de maior relevância para a seleção. Essa análise gera, portanto, estimativas mais acuradas de causa e efeito, e é uma ferramenta poderosa para o melhoramento.

No entanto, antes da aplicação da análise de trilha, deve-se fazer o diagnóstico de multicolinearidade dos dados, para evitar o viés nos resultados. Assim, há duas estratégias básicas para a análise de trilha: identificação e exclusão de variáveis responsáveis pela colinearidade; ou análise de trilha com regressão em crista, no caso de não se desejar a eliminação de variáveis. Nesta segunda estratégia, utiliza-se uma constante $\mathrm{k}$, cujo valor deve ser o menor possível, para estabilizar os coeficientes de trilha e manter o fator de inflação da variância (VIF) menor que 10, em todas as variáveis explicativas (Cruz \& Carneiro, 2006; Rios et al., 2012).

A aplicabilidade da análise de trilha, na detecção de caracteres úteis para seleção indireta quanto ao peso ou à produção de frutos, foi demonstrada, entre outras espécies para mamoeiro (Carica papaya L.) por Oliveira et al. (2010); açaizeiro (Euterpe oleracea Mart.) por Teixeira et al. (2012); e maracujazeiro-azedo (Passiflora edulis Sims) por Lúcio et al. (2013). O uso da seleção indireta pode acelerar a obtenção de genótipos promissores, uma vez que são escolhidos caracteres de fácil mensuração, alta herdabilidade, medição precoce e altamente correlacionados a outros caracteres que, embora mais importantes, são de difícil obtenção (Cruz \& Carneiro, 2006). Assim, dada a importância da análise de trilha para o melhoramento de frutíferas, é surpreendente que não tenham sido encontrados na literatura estudos com a jabuticabeira e tampouco com outras espécies frutíferas da família Myrtaceae.

O objetivo deste trabalho foi identificar os efeitos diretos e indiretos de caracteres dos frutos de jabuticabeira sobre o rendimento de polpa e o teor de antocianinas na casca.

\section{Material e Métodos}

Foram coletados frutos de 36 jabuticabeiras adultas, de idade desconhecida, nativas de fragmentos florestais de cinco municípios da região Sudoeste do Paraná, cujos caracteres foram descritos por Danner et al. (2010, 2011). Em cada sítio, de duas a nove jabuticabeiras foram selecionadas no momento da colheita, em setembro-outubro de 2007. Cada jabuticabeira foi dividida em quatro quadrantes (norte, sul, leste e oeste), tendo-se coletado 25 frutos em cada um deles (repetições).

No laboratório, realizou-se a lavagem e a avaliação de dez caracteres dos frutos: peso médio e diâmetro, obtidos com paquímetro digital; percentagem de semente e de casca; rendimento de polpa (\%); número de sementes por fruto; e teores de sólidos solúveis totais (SST), acidez titulável (AT), antocianinas e flavonoides na casca. O teor de SST ( ${ }^{\circ}$ Brix) foi medido com refratômetro digital, a partir da polpa extraída dos frutos, e a AT (percentagem de ácido cítrico) foi determinada por meio da titulação (solução de $\mathrm{NaOH}$ a $0,1 \mathrm{~mol} \mathrm{~L}^{-1}$ ), até $\mathrm{pH} 8,1$, de $10 \mathrm{~mL}$ de polpa diluída em $90 \mathrm{~mL}$ de água destilada. As amostras de casca foram armazenadas em freezer, a $-18^{\circ} \mathrm{C}$, e, posteriormente, analisadas quanto ao teor de antocianinas e de flavonoides, de acordo com Lees \& Francis (1972), em amostra de $0,5 \mathrm{~g}$ de casca.

Foram estimados os coeficientes de correlação de Pearson entre os caracteres, cuja significância foi avaliada pelo teste t de Student, a 1\% de probabilidade. Aplicou-se o teste de Lilliefors para verificar a aderência dos dados à distribuição normal. Em seguida, realizouse o diagnóstico de multicolinearidade por meio da análise do número de condição (NC), que representa a razão entre o maior e o menor autovalor da matriz de correlações. Segundo Montgomery \& Peck (1981), se $\mathrm{NC}<100$, a colinearidade é fraca; se $100<\mathrm{NC}<1.000$, a colinearidade é de moderada a forte; e se $\mathrm{NC}>1.000$, a colinearidade é severa.

Com a constatação de multicolinearidade moderada ou severa, realizou-se a análise de trilha por meio de duas estratégias, para evitar viés nos dados: a primeira excluiu uma variável para reduzir o $\mathrm{NC}$ abaixo de 100 , com posterior análise de trilha com as variáveis restantes; e a segunda realizou a análise de regressão em crista, ou a análise de trilha sob multicolinearidade, proposta por Carvalho (1994), com todas as variáveis. Além disso, duas análises de trilha foram realizadas: uma ao se considerar o percentual de polpa como variável básica (dependente principal), com os caracteres peso e diâmetro de fruto, percentual de sementes e de casca, e número de sementes considerados como independentes ou explicativos; e outra ao se considerar o teor de antocianinas na casca como variável básica, com os caracteres percentual de sementes, polpa e casca, e 
teores de SST, AT e de flavonoides como explicativos. As análises foram realizadas com o programa Genes (Cruz, 2013).

A interpretação dos efeitos dos coeficientes de trilha foi feita a partir dos coeficientes de correlação de Pearson (r), conforme Lúcio et al. (2013): quando o $\mathrm{r}$ e o efeito direto foram semelhantes em magnitude e sinal, a correlação explicou bem a associação entre as variáveis; se o $r$ foi positivo e o efeito direto, próximo a zero ou negativo, a correlação foi ocasionada pelos efeitos indiretos; quando o $\mathrm{r}$ esteve próximo a zero e o efeito direto foi positivo e alto, os efeitos indiretos foram considerados os responsáveis pela falta de correlação; e se o $r$ foi negativo e o efeito direto foi positivo e alto, ignoraram-se os efeitos indiretos e consideraram-se apenas os diretos.

\section{Resultados e Discussão}

As variáveis analisadas apresentaram distribuição normal, de acordo com o teste de Lilliefors, não tendo sido necessária a transformação dos dados. Todas as correlações de Pearson entre os caracteres avaliados foram significativas, a $1 \%$ de probabilidade.

$\mathrm{Na}$ análise de trilha realizada com o rendimento de polpa como variável básica (Tabela 1), o grau de multicolinearidade encontrado no conjunto de seis caracteres foi severo, com NC muito maior que 1.000 $\left(5,15 \times 10^{9}\right)$. A análise de trilha com exclusão do caráter percentual de casca proporcionou expressiva redução do NC entre os cinco caracteres restantes, com valor de 47,39, que é considerado baixo (Montgomery \& Peck, 1981). Na comparação entre os tipos de análise, verificou-se que o coeficiente de determinação foi de 0,99 , para análise sob multicolinearidade, e de 0,13 , para análise com exclusão, e que o efeito da variável residual foi de 0,01 e de 0,93 , respectivamente. Como o coeficiente de determinação sob multicolinearidade foi maior e o efeito da variável residual, menor, a análise com seis caracteres e com uso da regressão em crista (análise de trilha sob multicolinearidade) mostrou-se mais confiável para explicar os efeitos dos caracteres sobre a variável básica (Cruz \& Carneiro, 2006). Entretanto, Toebe \& Cargnelutti Filho (2013), em milho (Zea mays L.), e Carvalho et al. (1999), em pimentão (Capsicum annuum L.), observaram que tanto a análise de trilha com eliminação de variáveis quanto a análise de trilha com regressão em crista são eficientes para minimizar os efeitos de multicolinearidade severa.
A análise de trilha sob multicolinearidade revelou que o percentual de casca apresentou maior correlação $(-0,99)$ e maior efeito direto $(-0,97)$ sobre o caráter base

Tabela 1. Estimativa dos efeitos diretos e indiretos de caracteres dos frutos de jabuticabeira (Plinia cauliflora) sobre o rendimento de polpa, por meio da análise de trilha sob multicolinearidade (regressão em crista) ou com a exclusão do caráter percentual de casca.

\begin{tabular}{|c|c|c|}
\hline Via de associação & $\begin{array}{l}\text { Sob multicoli- } \\
\text { nearidade }^{(1)}\end{array}$ & $\begin{array}{c}\text { Exclusão do } \\
\text { percentual de casca }\end{array}$ \\
\hline & \multicolumn{2}{|c|}{ Peso de fruto } \\
\hline Efeito direto sobre $\%$ de polpa & 0,006 & 0,798 \\
\hline Efeito indireto via diâmetro & $-0,004$ & $-0,622$ \\
\hline Efeito indireto via \% de sementes & 0,086 & 0,044 \\
\hline Efeito indireto via $\%$ de casca & 0,103 & - \\
\hline Efeito indireto via $\mathrm{n}^{\circ}$ de sementes & 0,000 & $-0,028$ \\
\hline \multirow[t]{2}{*}{ Efeito total (correlação de Pearson) } & $0,192 * *$ & $0,192 * *$ \\
\hline & \multicolumn{2}{|c|}{ Diâmetro de fruto } \\
\hline Efeito direto sobre $\%$ de polpa & $-0,004$ & $-0,658$ \\
\hline Efeito indireto via peso de fruto & 0,006 & 0,754 \\
\hline Efeito indireto via \% de sementes & 0,085 & 0,043 \\
\hline Efeito indireto via \% de casca & 0,024 & - \\
\hline Efeito indireto via $n^{0}$ de sementes & 0,000 & $-0,028$ \\
\hline \multirow[t]{2}{*}{ Efeito total (correlação de Pearson) } & $0,111 * *$ & $0,111 * *$ \\
\hline & \multicolumn{2}{|c|}{ Percentual de sementes } \\
\hline Efeito direto sobre $\%$ de polpa & $-0,157$ & $-0,079$ \\
\hline Efeito indireto via peso de fruto & $-0,003$ & $-0,439$ \\
\hline Efeito indireto via diâmetro & 0,002 & 0,356 \\
\hline Efeito indireto via \% de casca & $-0,037$ & - \\
\hline Efeito indireto via $\mathrm{n}^{\circ}$ de sementes & 0,000 & $-0,035$ \\
\hline \multirow[t]{2}{*}{ Efeito total (correlação de Pearson) } & $-0,196 * *$ & $-0,196 * *$ \\
\hline & \multicolumn{2}{|c|}{ Percentual de casca } \\
\hline Efeito direto sobre $\%$ de polpa & $-0,974$ & - \\
\hline Efeito indireto via peso de fruto & 0,000 & - \\
\hline Efeito indireto via diâmetro & 0,000 & - \\
\hline Efeito indireto via \% de sementes & $-0,006$ & - \\
\hline Efeito indireto via $\mathrm{n}^{\circ}$ de sementes & 0,000 & - \\
\hline \multirow[t]{2}{*}{ Efeito total (correlação de Pearson) } & $-0,987 * *$ & - \\
\hline & \multicolumn{2}{|c|}{ Número de sementes } \\
\hline Efeito direto sobre $\%$ de polpa & $-0,002$ & $-0,187$ \\
\hline Efeito indireto via peso de fruto & 0,001 & 0,118 \\
\hline Efeito indireto via diâmetro & $-0,001$ & $-0,098$ \\
\hline Efeito indireto via \% de sementes & $-0,029$ & $-0,015$ \\
\hline Efeito indireto via \% de casca & $-0,151$ & - \\
\hline \multirow[t]{2}{*}{ Efeito total (correlação de Pearson) } & $-0,182 * *$ & $-0,182 * *$ \\
\hline & \multicolumn{2}{|c|}{ Desempenho da análise } \\
\hline Coeficiente de determinação $\left(\mathrm{R}^{2}\right)$ & 0,9933 & 0,1298 \\
\hline Efeito da variável residual & 0,0082 & 0,9329 \\
\hline Número de condição & $5,15 \times 10^{9}$ & 47,388 \\
\hline Valor de k usado na análise & 0,0007 & - \\
\hline
\end{tabular}

${ }^{(1)}$ Os fatores de inflação da variância foram menores que 9,2, na análise de trilha sob multicolinearidade. **Significativo pelo teste $\mathrm{t}$, a $1 \%$ de probabilidade. 
rendimento de polpa (Tabela 1). Assim, esses caracteres tiveram uma verdadeira associação de causa e efeito, e o percentual de casca foi considerado como o caráter com o principal efeito determinante sobre o rendimento de polpa. Uma vez que esta associação é inversamente proporcional (sinal negativo dos coeficientes), a seleção de jabuticabas com menor quantidade de casca será efetiva na seleção indireta de frutos com maior rendimento de polpa. Danner et al. (2011) constataram que os rendimentos de polpa e de casca de jabuticabas foram os caracteres com maior contribuição $(93,5 \%)$ sobre a dissimilaridade genética, entre os genótipos avaliados no presente trabalho. Embora os caracteres peso e diâmetro de frutos sejam de fácil mensuração, eles não explicaram adequadamente o rendimento de polpa, pois a correlação de Pearson desses caracteres com a variável básica foi baixa $(0,11-0,19)$ e o efeito direto foi praticamente nulo.

A forte relação direta observada entre o percentual de casca e o rendimento de polpa explica a elevada colinearidade desta associação, e é a razão porque a exclusão do percentual de casca não foi um procedimento adequado para a análise de trilha, apesar de ter reduzido o $\mathrm{NC}(\mathrm{NC}<100)$. Já a análise de trilha sob multicolinearidade foi adequada, pois permitiu manter, no conjunto de dados, a variável mais explicativa sobre o rendimento de polpa.

Negreiros et al. (2007) observaram que a seleção de frutos com maior diâmetro equatorial possibilita a obtenção de maracujás-amarelos mais pesados e com maior rendimento de polpa, e que esse rendimento pode ser selecionado indiretamente com base na menor espessura da casca. Lúcio et al. (2013) relataram que os caracteres peso médio de polpa e número de frutos tiveram maior efeito no peso total de frutos de maracujazeiro-azedo, do que SST, peso, comprimento e diâmetro do fruto, espessura da casca e rendimento de polpa. Em açaizeiro, Teixeira et al. (2012) verificaram que o peso de frutos por cacho, o número de cachos e o número de ráquilas por cacho foram os principais determinantes à variação da produção de frutos por planta.

$\mathrm{Na}$ análise de trilha com o teor de antocianinas na casca como variável básica (Tabela 2), o grau de multicolinearidade obtido no conjunto de seis caracteres foi de moderado a forte, com $\mathrm{NC}=420,5$. Com a exclusão do rendimento de polpa, o $\mathrm{NC}$ caiu para 31,03 , entre os cinco caracteres restantes, que é considerado baixo (Montgomery \& Peck, 1981). Ao contrário da análise de trilha anterior, o coeficiente de determinação e o efeito da variável residual foram

Tabela 2. Estimativa dos efeitos diretos e indiretos de caracteres dos frutos de jabuticabeira (Plinia cauliflora) sobre o teor de antocianinas na casca, por meio da análise de trilha sob multicolinearidade (regressão em crista) ou com a exclusão do caráter percentual de polpa.

\begin{tabular}{|c|c|c|}
\hline Via de associação & $\begin{array}{l}\text { Sob multicoli- } \\
\text { nearidade }^{(1)}\end{array}$ & $\begin{array}{c}\text { Exclusão do } \\
\text { percentual de polpa }\end{array}$ \\
\hline & \multicolumn{2}{|c|}{ Percentagem de polpa } \\
\hline Efeito direto sobre antocianinas & 0,429 & - \\
\hline Efeito indireto via \% de casca & $-0,347$ & - \\
\hline Efeito indireto via SST & 0,250 & - \\
\hline Efeito indireto via AT & 0,052 & - \\
\hline Efeito indireto via flavonoides & 0,249 & - \\
\hline \multirow[t]{2}{*}{ Efeito total (correlação de Pearson) } & $0,635 * *$ & - \\
\hline & \multicolumn{2}{|c|}{ Percentagem de casca } \\
\hline Efeito direto sobre antocianinas & 0,351 & $-0,079$ \\
\hline Efeito indireto via \% de polpa & $-0,423$ & - \\
\hline Efeito indireto via SST & $-0,275$ & $-0,268$ \\
\hline Efeito indireto via AT & $-0,056$ & $-0,046$ \\
\hline Efeito indireto via flavonoides & $-0,250$ & $-0,257$ \\
\hline \multirow[t]{2}{*}{ Efeito total (correlação de Pearson) } & $-0,651 * *$ & $-0,651 * *$ \\
\hline & \multicolumn{2}{|c|}{ Teor de sólidos solúveis totais (SST) } \\
\hline Efeito direto sobre antocianinas & 0,476 & 0,464 \\
\hline Efeito indireto via \% de polpa & 0,225 & - \\
\hline Efeito indireto via \% de casca & $-0,203$ & 0,046 \\
\hline Efeito indireto via AT & 0,072 & 0,059 \\
\hline Efeito indireto via flavonoides & $-0,152$ & 0,156 \\
\hline \multirow[t]{2}{*}{ Efeito total (correlação de Pearson) } & $0,725 * *$ & $0,725 * *$ \\
\hline & \multicolumn{2}{|c|}{ Teor de acidez titulável (AT) } \\
\hline Efeito direto sobre antocianinas & $-0,084$ & $-0,068$ \\
\hline Efeito indireto via \% de polpa & $-0,269$ & - \\
\hline Efeito indireto via \% de casca & 0,236 & $-0,053$ \\
\hline Efeito indireto via SST & $-0,413$ & $-0,402$ \\
\hline Efeito indireto via flavonoides & $-0,183$ & $-0,189$ \\
\hline \multirow[t]{2}{*}{ Efeito total (correlação de Pearson) } & $-0,713 * *$ & $-0,713 * *$ \\
\hline & \multicolumn{2}{|c|}{ Teor de flavonoides } \\
\hline Efeito direto sobre antocianinas & 0,403 & 0,415 \\
\hline Efeito indireto via \% de polpa & 0,264 & - \\
\hline Efeito indireto via \% de casca & $-0,218$ & 0,049 \\
\hline Efeito indireto via SST & 0,179 & 0,175 \\
\hline Efeito indireto via AT & 0,038 & 0,031 \\
\hline \multirow[t]{2}{*}{ Efeito total (correlação de Pearson) } & $0,670 * *$ & $0,670 * *$ \\
\hline & \multicolumn{2}{|c|}{ Desempenho da análise } \\
\hline Coeficiente de determinação & 0,7186 & 0,7147 \\
\hline Efeito da variável residual & 0,5305 & 0,5341 \\
\hline Número de condição & 420,50 & 31,03 \\
\hline Valor de $\mathrm{k}$ usado na análise & 0,0007 & - \\
\hline
\end{tabular}

${ }^{(1)}$ Os fatores de inflação da variância foram menores que 9,2, na análise de trilha sob multicolinearidade. ${ }^{* * S i g n i f i c a t i v o ~ p e l o ~ t e s t e ~ t, ~ a ~} 1 \%$ de probabilidade. 
praticamente iguais entre as duas estratégias de análise de trilha: 0,71 e 0,53 , respectivamente. Isso indica que, quando a presença de multicolinearidade não é tão severa, não há grande efeito da correção pela análise de regressão em crista. $\mathrm{O}$ alto efeito da variável residual $(0,53)$ mostra que o conjunto de seis variáveis não explica totalmente a variação no teor de antocianinas na casca de jabuticabas, uma vez que seus valores superam os dos principais efeitos diretos e indiretos. Dessa forma, a variação observada no teor de antocianinas também se deveu a outros caracteres não mensurados no presente trabalho (Cruz \& Carneiro, 2006), como firmeza do fruto e espessura da casca, por exemplo.

A análise de trilha sob multicolinearidade revelou que os caracteres rendimento de polpa e teores de SST e de flavonoides explicam a maior parte da variação encontrada no teor de antocianinas na casca (Tabela 2). Isso porque o efeito direto entre esses três caracteres e a variável básica foi de pouco mais da metade do valor do coeficiente de correlação de Pearson. Além disso, quando a associação de cada um desses três caracteres foi avaliada com a variável básica, os outros dois caracteres de fora da avaliação apresentaram alto efeito indireto. Segundo Cruz \& Carneiro (2006), no caso de alta correlação e baixo efeito direto, a melhor estratégia para proporcionar ganhos satisfatórios na variável principal é a seleção simultânea das variáveis, com ênfase, também, naquelas cujos efeitos indiretos sejam significativos. Assim, o rendimento de polpa e o teor de SST, que são de fácil mensuração, podem ser usados para seleção indireta no aumento do teor de antocianinas na casca. O teor de flavonoides, apesar da associação significativa observada, não traz vantagem prática para seleção indireta, pois as metodologias de análise de flavonoides e de antocianinas são as mesmas; apenas se diferenciam quanto ao comprimento de onda para leitura no espectrofotômetro, ao final da reação (Lees \& Francis, 1972).

A associação entre o teor de SST (composto na maior parte por açúcares) e o teor de antocianinas pode ser explicada pelo fato de o gene de expressão da enzima chalcona sintase, responsável pela síntese de antocianinas, demandar açúcares para ativação (Boss et al., 1996). Larronde et al. (1998) observaram relação direta entre o acúmulo intracelular de glicose e frutose e o teor de antocianinas, em cultura de células de uva (Vitis vinifera L.). Este fato é muito importante, uma vez que possibilitaria a seleção de jabuticabas com maior teor de açúcares e de antocianinas na casca, ao mesmo tempo. O teor de antocianinas na casca deve ser alvo de seleção, para que se possa explorar o potencial da jabuticaba como alimento funcional, em razão dos efeitos benéficos deste composto à saúde humana (Leite-Legatti et al., 2012; Lenquiste et al., 2012). Danner et al. (2011) relataram teor de antocianinas na casca de jabuticabas de 367 a $1.420 \mathrm{mg} 100 \mathrm{~g}^{-1}$, o que evidencia elevada variabilidade e torna o caráter alvo potencial para seleção de genótipos.

Embora ambas as estratégias de análise de trilha tenham sido eficientes para minimizar os efeitos da multicolinearidade severa, o processo de escolha e descarte de variáveis é difícil, e muitas análises-teste precisam ser realizadas até que se obtenha uma multicolinearidade que seja baixa $(\mathrm{NC}<100)$. Além disso, a análise de trilha com regressão em crista tem as vantagens adicionais de considerar todas as variáveis e de tornar possível a realização de apenas uma análise.

\section{Conclusões}

1. O percentual de casca é útil para seleção indireta do rendimento de polpa de jabuticabas (Plinia cauliflora), e a seleção para menor quantidade de casca aumenta o rendimento de polpa.

2. O rendimento de polpa e o teor de sólidos solúveis totais, em conjunto, são úteis para a seleção indireta quanto ao teor de antocianinas na casca de jabuticaba.

\section{Agradecimentos}

À Coordenação de Aperfeiçoamento de Pessoal de Nível Superior (Capes) e à Fundação Araucária, pela concessão de bolsas; e ao Conselho Nacional de Desenvolvimento Científico e Tecnológico (CNPq), pela concessão de bolsa de produtividade.

\section{Referências}

BALERDI, C.F.; RAFIE, R.; CRANE, J. Jaboticaba (Myrciaria cauliflora, Berg.) a delicious fruit with an excellent market potential. Proceedings of the Florida State Horticultural Society, v.119, p.66-68, 2006.

BOSS, P.K.; DAVIES, C.; ROBINSON, S.P. Analysis of the expression of anthocyanin pathway genes in developing Vitis vinifera L. cv Shiraz grape berries and the implications for pathway regulation. Plant Physiology, v.111, p.1059-1066, 1996. 
CARVALHO, C.G.P. de; OLIVEIRA, V.R.; CRUZ, C.D.; CASALI, V.W.D. Análise de trilha sob multicolinearidade em pimentão. Pesquisa Agropecuária Brasileira, v.34, p.603-613, 1999. DOI: 10.1590/S0100-204X1999000400011.

CARVALHO, S.P. de. Métodos alternativos de estimação de coeficientes de trilha e índices de seleção, sob multicolinearidade. 1994. 163p. Tese (Doutorado) - Universidade Federal de Viçosa, Viçosa.

CRUZ, C.D. GENES - a software package for analysis in experimental statistics and quantitative genetics. Acta Scientiarum. Agronomy, v.35, p.271-276, 2013. DOI: 10.4025/ actasciagron.v35i3.21251.

CRUZ, C.D.; CARNEIRO, P.C.S. Modelos biométricos aplicados ao melhoramento genético. Viçosa: Ed. da UFV, 2006. 579p.

DANNER, M.A.; CITADIN, I.; SASSO, S.A.Z.; SCARIOT, S.; BENIN, G. Genetic dissimilarity among jabuticaba trees native to Southwestern Paraná, Brazil. Revista Brasileira de Fruticultura, v.33, p.517-525, 2011. DOI: 10.1590/S0100-29452011005000078.

DANNER, M.A.; CITADIN, I.; SASSO, S.A.Z.; TOMAZONI, J.C. Diagnóstico ecogeográfico da ocorrência de jabuticabeiras nativas no sudoeste do Paraná. Revista Brasileira de Fruticultura, v.32, p.746-753, 2010. DOI: 10.1590/S0100-29452010000300013.

LARRONDE, F.; KRISA, S.; DECENDIT, A.; CHÈZE, C.; DEFFIEUX, G.; MÉRILLON, J.M. Regulation of polyphenol production in Vitis vinifera cell suspension cultures by sugars. Plant Cell Reports, v.17, p.946-950, 1998. DOI: 10.1007/ s002990050515.

LEES, D.H.; FRANCIS, F.J. Standardization of pigment analyses in cranberries. HortScience, v.7, p.83-84, 1972.

LEITE-LEGATTI, A.V.; BATISTA, Â.G.; DRAGANO, N.R.V.; MARQUES, A.C.; MALTA, L.G.; RICCIO, M.F.; EBERLIN, M.N.; MACHADO, A.R.T.; CARVALHO-SILVA, L.B. de; RUIZ, A.L.T.G.; CARVALHO, J.E. de; PASTORE, G.M.; MARÓSTICA JÚNIOR, M.R. Jaboticaba peel: antioxidant compounds, antiproliferative and antimutagenic activities. Food Research International, v.49, p.596-603, 2012. DOI: 10.1016/j. foodres.2012.07.044.

LENQUISTE, S.A.; BATISTA, A.G.; MARINELI, R. da S.; DRAGANO, N.R.V.; MARÓSTICA JÚNIOR, M.R. Freeze-dried jaboticaba peel added to high-fat diet increases HDL-cholesterol and improves insulin resistance in obese rats. Food Research International, v.49, p.153-160, 2012. DOI: 10.1016/j. foodres.2012.07.052.

LÚCIO, A.D.C.; STORCK, L.; KRAUSE, W.; GONÇALVES, R.Q.; NIED, A.H. Relações entre os caracteres de maracujazeiro-azedo. Ciência Rural, v.43, p.225-232, 2013. DOI: 10.1590/S0103-84782013000200006.

MONTGOMERY, D.C.; PECK, E.A. Introduction to linear regression analysis. New York: J. Wiley, 1981. 504p.

NEGREIROS, J.R. da S.; ÁLVARES, V. de S.; BRUCKNER, C.H.; MORGADO, M.A.D.; CRUZ, C.D. Relação entre características físicas e o rendimento de polpa de maracujá-amarelo. Revista Brasileira de Fruticultura, v.29, p.546-549, 2007. DOI: 10.1590/ S0100-29452007000300026.

OLIVEIRA, E.J. de; LIMA, D.S. de; LUCENA, R.S.; MOTTA, T.B.N.; DANTAS, J.L.L. Correlações genéticas e análise de trilha para número de frutos comerciais por planta em mamoeiro. Pesquisa Agropecuária Brasileira, v.45, p.855-862, 2010. DOI: 10.1590/S0100-204X2010000800011.

RIOS, S. de A.; BORÉM, A.; GUIMARÃES, P.E. de O.; PAES, M.C.D. Análise de trilha para carotenoides em milho. Revista Ceres, v.59, p.368-373, 2012. DOI: 10.1590/ S0034-737X2012000300011.

TEIXEIRA, D.H.L.; OLIVEIRA, M. do S.P. de; GONÇALVES, F.M.A.; NUNES, J.A.R. Correlações genéticas e análise de trilha para componentes da produção de frutos de açaizeiro. Revista Brasileira de Fruticultura, v.34, p.1135-1142, 2012. DOI: 10.1590/S0100-29452012000400022.

TEIXEIRA, L.N.; STRINGHETA, P.C.; OLIVEIRA, F.C. de. Comparação de métodos para quantificação de antocianinas. Revista Ceres, v.55, p.297-304, 2008.

TOEBE, M.; CARGNELUTTI FILHO, A. Não normalidade multivariada e multicolinearidade na análise de trilha em milho. Pesquisa Agropecuária Brasileira, v.48, p.466-477, 2013. DOI: 10.1590/S0100-204X2013000500002.

WRIGHT, S. Correlation and causation. Journal of Agricultural Research, v.20, p.557-585, 1921.

Recebido em 11 de agosto de 2014 e aprovado em 9 de fevereiro de 2015 